\title{
LA PERSISTENCIA DEL DESEO: COLIBRI DE SEVERO SARDUY
}

\author{
POR \\ RENE PRIETO \\ Southern Methodist University
}

\begin{abstract}
Quel que soit l'objet de l'interrogation du sujet: la naissance, l'ordre du monde ... l'objet réel de la recherche est le savoir sur le désir de l'AUTRE (la mère)。 P. Aulagnier-Spairani
\end{abstract}

Afirmaba Roland Barthes que toda obra de ficción es una metáfora del cuerpo y, más exactamente, del cuerpo erótico'. Severo Sarduy acató esta afirmación al pie de la letra e hizo con ella lo que Barthes nunca pudo. Pasó de la teoría a la práctica dramatizándola en tres novelas, Cobra (1973), Maitreyo (1978) y Colibri (1984). Originales no sólo, como se ha dicho, porque subviertan el concepto lineal de la historia y los cánones de la novela mimética, sino porque su au tor esgrime las respectivas tramas como un telón que encubre el verdadero caudal del texto y hace del hecho somero una región más transparente destinada a incitar el deseo de un lector que desarme, revele y posea esa verdad que tan eróticamente se insinúa en el relato.

Cobra, por ejemplo, es la historia de un travesti cuya más añorada meta parece ser la reducción de sus propios pies ${ }^{2}$. La reina del Teatro Lírico de Muñecas es espectacularmente perfecta, con la excepción de las extremidades que se empeña en encerrar en hormas, en castigar "con baños sucesivos de agua fría y caliente" (11), en meter en "armaduras de alambre" (11) para reducir su portentoso volumen. Poco a poco, sin embargo, el texto revela que el rechazo de los tan castigados apéndices es fundamentalmente un desplazamiento de quien se empecina "en ser cada vez más perfecta" (72) y termina entregándose a la complaciente cuchilla del doctor Ktazob que "en taimado raspadero tangerino arranca de un tajo lo superfluo y esculpe en su lugar lúbrica rajadura" (85). Tal

\footnotetext{
${ }^{1}$ En Le Plaisir du Texle, por ejemplo, donde revela sus inquictudes de lector con tanta liberalidad, Barthes declara: "Le texte a une forme humaine, c'est une figure, un anagramme du corps? Oui, mais de notre corps crotique". (Paris; Editions du Seuil, 1973) 30 .

${ }^{2}$ Severo Sarduy, Cobra, (Buenos Aires: Editorial Sudamericana, 1973). Todas las citas en este trabajo son tomadas de esta edición.
} 
rechazo del cuerpo resulta ser, como lo he demostrado en otra ocasión, una dramatización del ansia de castración llevada a cabo por el protagonista que se entrega a la cuchilla del facultativo cuyo nombre la designa por antonomasia, ya que $z o b$ significa falo y por lo tanto $[\mathrm{k}][\mathrm{ta}][\mathrm{zob}]$ define al que castra ${ }^{3}$. Es lógico entonces que tras dicha operación la protagonista aparezca transformada en mujer "desde los pies hasta el cuello" (126). Menos lógico, a primera vista, el que recupere su género masculino al final de la misma sección. ${ }^{4}$. $Y$ es que, por definición, la ficción nunca dura. Y menos aquélla que dramatiza el más imposible de los anhelos: la posesión del cuerpo materno. Curiosamente, no por imposible se extingue el deseo. De su persistencia nace, como un retorno de lo reprimido, toda la ficción de Sarduy y, más recientemente, Colibrit.

En esta novela, el escritor cubano introduce un deseo triangular que comprende a Colibrí, bailarin y luchador en un "bar rural junto al delta de un rio inmenso de América del Sur"6, a la Regente a cargo del mismo, y a un karateca japonés con quien Colibrí se evade de la jaula tropical donde a diario se exhibe. Tras un sinfín de ardides que comprenden un buen tercio del relato, la matrona - cuyo máximo afán es poseer el pájaro- logra apoderarse de él, aunque ni siquiera asi consigue hacerle suyo. Colibrí, rescatado por un gigantito cabezón, despliega por fin las facultades que lo hacen digno de su apodo y "se eleva con un brinco, como si hubiera alcanzado el cenit de su energía a lo largo de la fijeza, y el cautiverio no hubiera servido más que para reforzar el impulso de su salto, la inmobilidad de su vuelo, la rapidez de su flecha por el aire" (136). A partir de este momento, la historia se repite: una vez más el pájaro pone pies en polvorosa, una vez más se reúne con el Nipón. Juntos huyen hasta que "una horda instantánea y afelpada de cazadores, ojos irritados de sueño, manotas manchadas", los rodea (155). No para someterlos, sin embargo, sino para anunciarle a Colibrí: "Volverás para quemar. Para destruir. Eres el único que puede introducirse en la Casona y tomar el poder sin resistencia alguna" (158). Así mismo ocurre en "esta alegórica patraña" (166). Colibrí regresa y arrasa. Funda un nuevo local y ocupa el puesto de quien lo perseguía. Su

3 Además del desplazamiento metafórico que discuto en "The ambiviolent fiction of Severo Sarduy", Symposium, vol. 39, number 1, (Spring, 1985), vale notar que, según el Diccionario de la Lengua Española de la Real Academia, 16 $6^{\mathrm{a}}$ edición (Madrid: Espasa Calpe, 1939), "vestirse uno por los pies" significa "ser del sexo masculino" (p. 990). En toda evidencia, entonces, el rechazo de los pies en Cobra es, desde un principio, una negación de la masculinidad.

${ }^{4}$ Después de la castración, Cobra se mira en un espejo y al verse recuerda La Dama de las Camelias (121). Sin embargo, en el caṕtulo que sigue ("¿Que tal?"), misteriosos personajes rodean a la que es ahora mujer "desde los pies hasta el cuello" y una octogenaria pintarrajeada grita: "Es él", 129.

${ }^{5}$ Severo Sarduy, Colibrt (Barcelona: Editorial Argos Vergara, S.A., 1984). Todas las citas en este trabajo son tomadas de esta edicion.

${ }^{6}$ Colibrí, resumen del autor en la carátula de la edición de Argos Vergara. 
transformación es tan completa que al mirarse en el espejo, al final de la novela, ni él mismo se reconoce: "como si detrás del mercurio apareciera otro" (178)。

En este momento del relato se hace menester cruzar al otro lado del azogue, ya que esta trama es simplemente una fachada calcada sobre la más primordial geometría del deseo en la novela: el triángulo formado por el narrador, su padre, y el cuerpo textual en continuo proceso de evasión (evasión ya que un grupo de "esbirros coreógrafos" se roba el relato para llenarlo de "pompones, arcaísmos y mariconerías de novelas pastorales, adjetivos inútiles, sinónimos y antónimos, complicaciones gratuitas y palabras repetidas" [112]). Los "esbirros" transforman el decorado y el lenguaje original; su narración penetra Colibrí hasta tal punto que el autor se dispone a quemar el manuscrito para poner fin al despojo de una vez por todas. Sin embargo, llegado el momento de la verdad, los esbirros, "ante el peligro de cantar el manicero, vuelven a poner, en un verdadero desenfreno épico, preocupadísimas por la verosimilitud y la coherencia, el decorado original de la Casona" (112). Vuelve a entrar Colibrí tal y como era en un principio, pero todo ha cambiado. La Casona, "aquel templo de camioneros, que perfumaba el tufo de la tuercas engrasadas ... aquel recio androceo ... se había convertido, believe it or not, en un inofensivo falansterio, o si se prefiere, en un sofisticado salón de té" (113). El relato continúa su vaivén en busca de autor y el capítulo termina con la voz del padre dirigida al hijonarrador que se prepara a sacrificar "las páginas más ignominiosas que [le] han impuesto" los esbirros coreógrafos:

"iHabráse visto!" -interpela el padre— "Otra vez quemando papeles! ¡Qué manía la tuya, chico! No pierdes ya bastante tiempo escribiéndolos; después les das candela ... ¡̈Chico qué barbaridad! Y mira ... voy a hablarte sonante y cantante. Ya tú eres un hombre y de los Sarduy, hasta ahora, no ha habido ningún pájaro. Y no quiero que nadie me señale en la calle. Así es que, ahora mismo vas a quemar también esas cuatro mierdas. ¿Quién ha visto a un hombre jugando con fruticas de brilladera?" (129)

La reprimenda paterna resulta ser capital no sólo para la comprensión, sino Lambién para la creación de Colibrí, ya que comprende la denegación del narrador, pues esta novela, toda ella, se fragua como una oposición a la ley del padre $^{7}$. El rechazo se anuncia en torno a "las cuatro mierdas" que parecen ser una alusión a las fruticas de brilladera que rodean la cabecita enturbantada de la Enana disfrazada de Carmen Miranda en el mismo capítulo: "platanitos de

\footnotetext{
${ }^{7}$ La voz del padre en Colibri debe verse en todo momento como una alusión a la norma impuesta por la autoridad durante el desarrollo psíquico. No sólo podemos sino que debemos aludir a este desarrollo porque las tres últimas novelas de Sarduy son en todo sentido vehículos por medio de los cuales el autor dramatiza (es decir alegoriza en forma de ficción) las pulsiones de su propia psique tales como el anhelo del cuerpo materno y el rechazo del padre.
} 
plástico, nueces de brilladera, un melocotón de strass dorado y una frambuesa" (128). Y digo que parecen ser una alusión porque el tópico del monólogo paterno no es la aventura de la Enana sino, con toda evidencia, la escritura (tal y como lo confirman las referencias a "páginas ignominiosas", "quemando papeles", y "pierdes ... tiempo escribiéndolos").

El padre del narrador no quiere que nadie lo señale en la calle y afirma que no ha habido ningún pájaro en la familia. Insinúa, además, que "las cuatro mierdas" están vinculadas con la acusada perversión y que destruirlas equivaldría a anular la tara que mancha el nombre de Sarduy. Implícitamente, la voz paterna desautoriza no sólo la inclinación sexual del hijo sino, más tenazmente, la sublimación de esta sexualidad que es la escritura: "así es que, ahora mismo vas a quemar también esas cuatro mierdas" (129). Dado el nexo entre escritura y transgresión sexual en la ingerencia paterna, ¿es posible no ver en "las cuatro mierdas" los cuatro relatos - Gestos, De donde son los cantantes, Cobra y Maitreya - que identifican claramente la homosexualidad del autor y que, dada su vocación transgresiva, simbolizan en todo sentido la ruptura con el padre y, al mismo tiempo, con la identidad normativa que su autoridad le impone como fardo y máscara a Severo Sarduy?

Examinemos con más detalle esta identidad. Mucha tinta ha corrido sobre la prosa transgresiva de Sarduy, poca sobre sus fuentes. Y, sin embargo, éstas brotan claramente a ojos del especialista que las busca reflejadas en el nombre debido. Sarduy exhibe su linaje irónico (ya que invertidamente) en el apelativo que en nuestra lengua encarna la ley: "Severo". Severo, que traducimos por" "serio, grave, austero, rigido, exacto, mesurado, estricto, puritano ...", acepciones todas que el autor ha pasado su vida desacreditando. "Severo", que hubiese sido sin duda su identidad si hubiese habido interiorización del nombre del padre, en cuyo caso no hubiese habido quizá literatura o, por lo menos, no un barroco de la transgresión. Porque su escritura es, ante todo, un desafío al orden establecido, un perpetuo rechazo, en otras palabras, de un "severo" deseo. Este desafío se hace evidente desde el título mismo de su novela más reciente, donde se acopla su apellido con la tara _el nombre de un pájaro que su padre le impugna. ¿No es Colibrí, entonces, en el más amplio sentido de la palabra, la respuesta del escritor de la transgresión al por ésta desautorizado autor que lo ultraja en el tex to antes citado? ¿Y qué puede acarrear esta negación de la ley paterna sino un deseo de la única opción accesible tras negar al padre: es decir, el cuerpo materno? Urge apuntar este deseo por ser esencial para el entendimiento de toda la obra de Sarduy. De él se desprende, según Julia Kristeva, el cariz semiótico que caracteriza al "yo" antes de alcanzar la fase normativa que la misma autora denomina "simbólica" y cuya expresión integral es el padre, es decir, la ley". Según Kristeva, lo semiótico designa el tipo de

\footnotetext{
${ }^{8}$ Diccionario de Sinonimos, Ideas Afines y Contrarios (Barcelona: Editorial Teide, S.A. 1966) 426.

${ }^{9}$ Vale notar además que, según el psicoanálisis, al trascender de la modalidad semiótica a la simbólica empieza a producirse ( 0 , mejor dicho, a proferirse) el lenguaje y se establece la sintaxis. Julia Kristeva, Polylogue (Paris: Editions du Scuil, 1977) 14.
} 
articulación descosida que asoma en juegos de palabras, en doble y contra sentidos, en efracciones sintácticas, que constituyen el tipo de literatura cuya meta es quebrantar el discurso normativo característico de la autoridad paterna ${ }^{10}$. La fase semiótica está separada de la simbólica por la realización del Edipo, etapa durante la cual la interdicción del cuerpo vedado de la madre hecha por el padre rompe las ataduras con el primer objeto del deseo infantil y suscita la identificación con la norma. Ahora bien, esta norma y esta identificación son las que Sarduy rechaza a todos los niveles. Tenemos, en su caso, una fijación 0 , más bien, un retorno a la pulsión semiótica.

Vale notar, no obstante, que es preciso que la castración haya sido un problema, un trauma, para que, prorrumpiendo a través de la postura simbólica, pueda sobrevenir una reversión hacia lo semiótico ${ }^{11}$. Este retorno de la pulsión reprimida caracteriza no sólo el discurso de la psicosis sino también, según Kristeva, la práctica del arte ${ }^{12}$. Esta opinión aparece confirmada en la obra de escritores como Joyce, Mallarmé y Sarduy, quienes agreden la función paterna no sólo en lo concerniente a su representación ideológica, sino también en todo lo que se refiere a su ejecución simbólica, es decir, al funcionamiento mismo de la lengua. Y aunque lo semiótico no pueda nunca excluir lo simbólico sin que la comunicación se extinga, sí puede (como vemos en Finnegan's Wake, en Cobra o en Maitreya) trasgredir el ordenado y constrictivo muro de la norma para hacer presente un desorden en una perspectiva lógica, sintáctica y morfológica que hasta ahora nos hemos limitado a llamar "neobarroca" en cuanto respecta a Sarduy. Esta etiqueta es insuficiente, sin embargo, ya que describe el resultado ignorando el síntoma que acusa su origen. Decir barroco supone un fenómeno exterior, decorativo; decir Sarduy implica una escritura que emana del fuero interno y que revela metafóricamente (a través de la trama, aunque no explícitamente), la fijación más profunda del autor al desautorizado cuerpo con el que se identifica hasta tal punto que transforma todo lo masculino en su contrario, travestiéndolo. No hay que ver en esta fijación, sin embargo,

${ }^{10}$ Ibid.

"Julia Kristeva, La révolution du langage póetique (Paris: Editions du Scuil, 1974) 49. Hay que ver que el ansia de castración tan fundamental en Cobra se transparenta igualmente en otras novelas de Sarduy. En Colibri, por cjemplo, el Japonesón aparece "con los atributos de Osiris suspendidos entre las patas delanleras", 76-77; Osiris fue cortado en pedazos, castrado por orden de su hermano Set, y su falo sirvió de alimento a los cangrejos del Nilo. New Larousse Encyclopedia of Mylhology (London \& New York: Prometheus Press, 1959) 18. Asimismo, en Maitreya, un gru po de vicjas corta al Nobilísimo Infante en cien pedazos declarando: "He aqui el cuerpo del hombre fragmentado..." y, añaden significativamente: "He aquí la causa del deseo," Mailreya (Barcelona, Caracas, México: Seix Barral, 1978) 74. Es evidente que todo el cariz semiótico y por ende transgresivo en la obra de Sarduy emana de esta fijación a la castración y de la consecuente identificación al cuerpo materno.

${ }^{12}$ Kristeva, Ibid, 67. 
única y exclusivamente un afán de contacto materno. El deseo de la madre es más bien el anhelo de "ser todo para ella, de condicionar su vida, de ser inconscientemente, el complemento de su carencia, es decir, el falo"13. Es más, según Lacan, al identificarse con el objeto del deseo del otro y ser el elemento pasivo, completamente dependiente de la madre, el niño no es un sujeto sino una carencia, una nada, lo que pone en claro la falta de identidad preponderante en la ficción de Sarduy ${ }^{14}$. Cobra es travesti, castrato, mujer, hombre y raíz cuadrada de sí misma. La Tremenda, protagonista de Maitreya, es también la Colosal, la Monumental, la Masiva, la Contundente, la Diva, la Prima, la Obesa, la Toda-Masa, la Delirium, la Divina, la Expansiva. Colibrí es zun-zun, zumbete, chupamirto, pájaro mosca y la Regente se emborrona la cara con estuco blanco "como si quisiera perder la identidad" (117). Tal fluctuación o inestabilidad del sujeto narrativo justifica que el mismo Colibri no se reconozca al mirarse al espejo ("como si detrás del mercurio apareciera otro" [178]), en una escena que no puede dejar de invocar - muy oportunamente, por lo demás-la celebrada fase descrita por Lacan ${ }^{15}$. Al igual que el niño durante la primera etapa de esta fase, Colibrí cree ver otro, un extraño, al mirarse en el espejo. Como el niño, no obstante, el pájaro llega a darse cuenta de que la imagen frente a sí es, de hecho, un reflejo, "que ce 'je' reflétant-reflétè ne renvoie à aucun terme extérieur", y termina reconociéndola, no como una representación exterior a su persona, sino como su propia imagen: "Fue su gesto de asombro lo que a sus propios ojos lo identificó" (78). Lacan, debo añadir, sitúa la realización del Edipo entre la segunda y tercera etapa y ubica entre ambas la interdicción paterna que constriñe a romper el lazo de identidad con la madre y le revela al niño su propia identidad. Tal y como lo afirma Kristeva,

La découverte de la castration détache le sujet de sa dépendence vis-à-vis de la mère, et à travers ce manque, fait de la fonction phallique une fonction symbolique. Moment décisif et lourd de conséquence: le sujet trouvant son

\footnotetext{
${ }^{13}$ Anika Lemaire, Jacques Lacan (Bruselas: Pierre Mardaga, éditeur, 1977) 140. En su seminario sobre la formación del inconsciente, al discutir el deseo infantil, Lacan declara: "Il est désir du désir de la mère et pour le satisfaire, il s'identifie à l'objet de ce désir: soit au phallus". "Les formations de l'inconscient". Seminarios de los años 1956"1957 en el Bulletin de Psychologie, 1956-57.

${ }_{14}$ Lacan llama este momento del desarrollo psíquico, la "captation imaginaire" y lo describe como una etapa durante la cual el individuo carece de substituto simbólico de sí mismo y, por lo tanto, se encuentra privado de individualidad (tal y como los protagonistas sarduyanos). Lemaire, 141.

${ }^{15}$ "Le stade du miroir comme formateur de la Fonction de $\mathrm{Je}$, en Ecrits I (Paris: Editions du Seuil, Coll. "Points", 1966) 89. Es verdad que esta fase no deja de haberse vuclto un lugar común en muchos trabajos de envergadura psicoanalítica, pero cuán oportuna y cuán inevitablemente viene al caso al discutir un autor cuyo afán artístico es la sublimación de un deseo (el cuerpo de la madre) vinculado en todo sentido al problema de la identidad.
} 
identité dans le symbolique, se sépare de son implication dans la mère, localise sa jouissance comme genitale, et transfere la motilité sémiotique dans l'ordre symbolique ${ }^{18}$.

Pero esta transferencia es justamente la que no ocurre en las novelas de Sarduy. Tendríamos una traslación de la identificación con la figura del padre y un avance hacia el impulso genital si el Edipo se resolviera de manera satisfactoria, si la castración simbólica impuesta por el padre prohibiera, de una vez por todas, el cuerpo de la madre. Pero Sarduy no sólo niega la castración (Cobra castrado re-cobra el género perdido), sino que refuta al padre que lo rechaza al producir una obra que transgrede la norma en todo sentido y el decreto paterno ("quema también esas cuatro mierdas") por el simple hecho de existir. El hecho de negarlos afirma al mismo tiempo la fijación terminante de su obra, el deseo de la madre, y determina la pulsión sexual ubicua en ésta.

Desde el punto de vista de la pulsión libidinal, la segunda y tercera infancia están caracterizadas por la fase anal (la segunda) y genital (la tercera). Al rechazar la interdicción paterna que adviene entre ambas, la libido se mantiene arraigada a la segunda, que Freud vincula a la agresión, al sadismo y a la pulsión de muerte ${ }^{17}$. Al traducir en términos literarios la fijación al cuerpo materno y el correspondiente apego a la segunda fase de la libido, desembocamos directamente en la fantasía sadomasoquista de Sarduy. En Colibri, por ejemplo, lo que más disfrutan los clientes de la Casona "era la tortuosa voluptuosidad de obedecer" y por esta razón "arremetían los fanfarrones contra los más frágiles" (17). A través de la novela prevalecen "el código de los escarnios" (17), los "quejidos y acezos" (17), "el chiquetazo en el ano" (18) y las "sandeces elocutorias" (22). Los protagonistas se humillan sin cesar y tanto el cuerpo de Colibrí como el de la Regente aparecen ora vejados, "salpicados de coágulos ... estriado por las sogas, tachado por latigazos y escupitajos" (50) ora desvencijados, con "pupilas opacas ... (y) la boca ... fijada en un rito desdentado" (52).

En su expreso sadismo, por lo tanto, "la patraña punitiva" (55) que se representa en la Casona traduce claramente la pulsión anal que antecede al emplazamiento de lo simbólico. Pero Sarduy no se limita a trasladar una sola característica de esta fase. La "retención simbólica, el afán de dominio y de poseer el mundo" que Norman O'Brown acusa como rasgos típicos de ésta son, de hecho, los impulsos que modelan (por no decir generan) la trama de una

\footnotetext{
${ }^{16}$ Julia Kristeva, La revolution du langage poetique, 45.

${ }^{17}$ Sigmund Freud, "La Negation”. (Revue francaise de psychanalyse, vol. 7, No. 2, 1934). También Julia Kristeva discute el nexo entre el placer de la destrucción y la pulsión anal en Polylogue (70) y Recherches pour une sémanalyse (Paris: Editions du Seuil, 1969). Según Kristeva, esta pulsión resulta en una negatividad que acarrea a su vez un sujeto heterogéneo, fragmentado en múltiples facetas tal y como los personajes en Cobra, Maitreya, y Colibrt.
} 
novela que podemos describir como un enfrentamiento por el poder ${ }^{18}$. Aunque, dicho sea de paso, Colibrí no es una excepción en lo que respecta a la figuración de la analidad. A partir de ésta emana la temática de toda la trilogía del deseo - Cobra, Maitreya, y Colibrí-donde prevalece el sadismo, el afán de dominio, la sodomía y la fijación con la muerte. La transcripción de Sarduy no ignora tampocoel instinto de rechazo (Ausstossung o Verwerfung) que Freud asocia con esta misma pulsión anal ${ }^{19}$. Según Freud, el desprendimiento y por consiguiente el rechazo de una parte del cuerpo - las heces fecales - provoca una división o un sentido de fragmentación. Tal sentido figura de manera primordial en la obra de Sarduy. Cobra, por ejemplo, se descubre una mañana empequeñecido, raíz cuadrada de sí mismo, pero en diálogo con su otro yo de tamaño normal. Más tarde, durante la escena de castración, la Reina del Teatro Lírico dirige su dolor hacia la enana, gracias a la "identificación somática" (108), mientras el narrador le explica: "No es más que tu desperdicio, tu residuo grosero, lo que de tí se desprende informe ... tu excremento, tus senos falsos ... cuerpo de tí caído que ya no eres tú" (115). En Maitreya "las desguazadoras" cortan al protagonista en pedazos, "uno a uno, hasta cien. Siguiendo con esmero las articulaciones: sin derrames serosos ni sanguineos" (73-74) y al terminar la operación, anuncian oportunamente: "He aquí el cuerpo del hombre fragmentado", anadiendo en seguida, "He aquí la causa del deseo" $(74)^{20}$. Finalmente, en Colibri, el desprendimiento y la fragmentación surgen en todos los niveles: primeramente y como fuente de otros tipos de rechazo-entre padre e hijo; en segundo lugar, entre el narrador y el texto que se escabulle y por último, entre los personajes

\footnotetext{
${ }^{18} \mathrm{Tal}$ y como lo apunta Norman O'Brown, "psychoanalytical theory stresses the interconnection between anal organisation and human aggression to the point of labeling this phase of infantile sexuality the analsadistic phase". "Defiance, mastery, will to power", añade O'Brown, "are attributes of human reason first developed in the symbolic manipulation of excrement and perpetuated in the symbolic manipulation of symbolic substitutes for excrement". Norman O'Brown, Life Against Dealh (Middletown: Wesleyan University Press, 1959) 192.

18 Sigmund Freud, Beyond the Pleasure Principle, trad. J. Strachey. (International Psycho-Analytical Library, ed. E. Jones, no. 4). London: Hogarth Press, 1950. También Julia Kristeva señala en Polylogue: "Les pulsions, traversant les sphineters, suscitent le plaisir au moment même où se détachent du corps des substances lui ayant appartenu et désormais rejetées en dehors. Plaisir aigu coincidant avec une perte, avec la séparation du corps et l'isolation hors de lui d'objets. C'est l'expérience fondamentale de la séparation, avant la position de l'altérité detachée du corps propre qui sera l'objet réel: une séparation qui n'est pas un manque, mais une décharge, et qui, pour être privative provoque du plaisir. Que cette perte en jou issance soit ressentie comme une attaque à la fois contre l'objet expulsé, contre tout objet extérieur (père - mère compris) et contre le corps lui-même, le psychanalyste le suppose" (71).

${ }^{20}$ Declaraciones de esta índole no dejan lugar a dudas del hecho que Sarduy expone su designio y desbroza el temple de su obra para todo lector dispuesto a indagar detrás de la fachada compuesta por la trama.
} 
que, como en toda la obra de Sarduy, se fragmentan en una serie de dobles y anamorfosis (Colibrí y la monja levita [74-75], por ejemplo, o el Gigantito cabezón y la Enanota albina [16]).

Es curioso, pero fácilmente comprensible, ver por qué las novelas de Sarduy forjan su unidad a base de la fragmentación, cuando examinamos ésta a la luz del rechazo característico de la fase dominante en su ficción. Al mismo tiempo, para aprehender el alcance de la analidad en su novelística, es imprescindible entender la fijación al cuerpo de la madre, que resulta, según hemos visto, como consecuencia del rechazo paterno (la negación del nombre del padre), la cual Sarduy retrata más claramente que nunca en Colibrí. Tan claramente, de hecho, que no podemos ignorar la presencia aqui, en esta novela, de una resolución.

Cobra, Maitreya y Colibrí declaran todas el mismo afán: el cuerpo obsesionante que los protagonistas desean poseer. Por esta razón me refiero a ellas como una trilogía. Sin embargo, al hermanarlas no quiero de ninguna manera sugerir que a través de la reiteración de un mismo deseo - el cuerpo de la madre- no haya, de una a otra, un desarrollo y, finalmente, un desenlace. Seré más explícito: la trilogía empieza con Cobra, donde se plantea formalmente el deseo de castración que identifica al protagonista con el cuerpo femenino: "Ya eres, Cobra, como la imagen que tenías de tí" (118), anuncia el instructor después de la emasculación. Maitreya, la novela que le sigue, autoriza (transformåndola y pervirtiéndola) la maternidad que simboliza la identificación con este mismo cuerpo ${ }^{21}$. Sin embargo, como se hace evidente en ambas ficciones, el anhelo tendiente a la homosexualidad, el deseo de la madre, es quimérico y, por ende, inalcanzable. Cobra recupera el género masculino a pesar de la castración que lo mutila sin hacerlo mujer: "Es él" (130) grita una voz que lo identifica cuando aparece vestido de mujer en el capítulo siguiente a la intervención de $\mathrm{Ktazob}^{22}$. La castración es una ficción que no podrá nunca llevar a efecto la transformación. La posesión, en otras palabras, es imposible verismo que se convierte en Colibrí. Imposible o no, el deseo es objeto primordial de la narración en toda la trilogía. Sólo que en Colibri Sarduy distingue por primera vez entre sus dos facetas: la anaclítica y la del narcisismo. La primera caracteriza la dependencia total de la madre y sostiene el deseo de posesión; la segunda se manifiesta como una identificación o, en otras palabras, como un

\footnotetext{
${ }^{21}$ Pervirtiéndola, ya que el hijo de la protagonista viene al mundo por vía anal, engendrado gracias al "consuelo digital" de un iranio que le hunde el puño hasta las falanges por el mismo "pasadizo escabroso" (178).

${ }^{22} \mathrm{Al}$ mismo tiempo, la transición de la tercera persona a la primera que se opera en el párrafo precedente amalgama a Cobra con el narrador. "El índice huesudo" que identifica a Cobra cruza, segrin nos indica el texto, "muy cerca de mis labios ..." (130) aludiendo, evidentemente, al nexo que existe entre el desco dramatizado por los personajes y el anhelo de la primera persona.
} 
afán de semejanza al objeto del deseo ${ }^{23}$. Es éste el modelo concluyente con que termina la novela más reciente de Sarduy. La narración de Colibrí, toda ella, niega la posesión, pero al final de la novela, después de acabar con la Casona y destruirlo todo, el protagonista llega a ocupar, "poco a poco, el lugar de quien lo persiguió", llevando asi a cabo una identificación con la regla representada por la Regente. La posesión imposible descrita en Cobra se ha transformado, paulatinamente, en objeto viable y Sarduy logra hacer suyo, por primera vez en su ficción, el celebrado epígrafe de Rimbaud, "je est un autre", al transformar al pájaro en detentor de la regla. Pero como toda figuración en su obra, esta regla es una inversión integral de la norma: no es orden sino desorden, es decir, transgresión, ya que la Regente es en todo sentido una parodia del padre travesti y proxeneta en un prostíbulo homosexual irónicamente llamado "la Casona".

Dado el doble rechazo de la ley (del padre por el narrador, de la Regente por Colibrí) y la identificación que hace del protagonista verbo encarnado de la transgresión, tenemos que reconocer entonces que Colibri es, desde todos los puntos de vista, un espejo de paciencia en el cual se vindica el autor. Y digo que se vindica porque en su novela más reciente Sarduy no anula sencillamente el nombre del padre, "Severo", sino que lo invierte como invierte la norma, la lógica y el sexo de sus personajes. Su obra, escrita sobre un cuerpo, es en todo momento, reflejo de su propia psique, reivindicación siempre reincidida de su propia identidad envuelta en el acto de ver-se. Verse que resulta ser el más palmario desafío al nombre del padre, Se-vero, invertido y convertido por el escritor en la revelación narcisística que define, en todo sentido, su insubordinación literaria.

\footnotetext{
${ }^{23}$ Sigmund Freud, Group Psychology and the Analysis of the Ego, trad. J. Strachey (London, Viena: The International Psycho-Analytical Press, 1922) 60-62 y también en New Introductory Lectures on Psychoanalysis, trad. W. J. Sprott (Londres: Hogarth Press and The Institute of Psychoanalysis, 1933) 86. En un ensayo tan lúcido como revelador, Sarduy analiza la posesión del cuerpo materno con lujo de detalles y concluye afirmando: "Adorar al Otro, es convertirse en él". Escrito sobre un cuerpo (Buenos Aires: Editorial Sudamericana, 1969) 39.
} 